\title{
A educação de menores abandonados segundo o discur- so médico-jurídico na Argentina e no Brasil da transição dos séculos XIX/XX. Uma contribuição aos estudos compa- rados do pensamento educacional na América Latina
}

\author{
José Luiz M. Villar*
}

\section{Resumo}

O menor abandonado representava uma ameaça ao ideário e aos princípios do positivismo que fundamentavam o saber médico e o discurso jurídico. Ele era a materialização da imprevisibilidade da desordem social, uma ameaça ao progresso e à modernização da sociedade. Neste sentido, ameaçava ainda um pensamento educacional que se colocava como principal instrumento, a partir do otimismo pedagógico, da instalação e manutenção de padrões europeus de civilização na América Latina como herança automática, dependência cultural, do período colonizatório.

\section{Palavras chave}

Pensamento Educacional, educação de menores abandonados, estudos comparados da educação latino-americana, séculos XIX e XX

Recepció original: 31 de març de 2021

Acceptació: 20 de maig de 2021

Publicació: 1 de juliol de 2021

\section{Introdução: Do herói mítico fundador à ameaça a uma ordem instituída}

A História da antiguidade está pontuada pelas trajetórias de menores abandonados que se constituíram em divindades ou mitos fundadores de povos e civilizações. Assim foi com Rômulo e Remo, fundadores de Roma; com Édipo, Rei de Tebas; com Despina, ou Despoina, divindade das sombras e do inverno; ou com Moisés, legislador e liderança dos Hebreus (Freud, 1939 e 2014). O que essas histórias tinham em comum era a sua relação com a construção de uma identidade cultural, a construção de um processo de pertencimento, o estabelecimento de novos rumos ou trajetórias para diferentes sociedades. Dito em outras palavras, também nos faz lembrar que toda criança teria a potencialidade para se manifestar como mito fundador, como um iniciador, criando novas trajetórias, narrativas, numa sociedade no tempo:

\footnotetext{
O fato de que o Homem é capaz de agir significa que se pode esperar dele o inesperado, que ele é capaz de realizar o infinitamente provável. E isto, por sua vez, só é possível porque cada Homem é singular, de sorte que a cada nascimento, vem ao mundo algo singularmente novo. Desse alguém que é singular pode-se dizer, com certeza, que antes dele não havia ninguém. Se a ação, como início, corresponde ao fato do nascimento, se é a efetivação da condição humana da natalidade, o discurso corresponde ao fato da distinção e é a efetivação da condição humana da pluralidade, isto é, do viver como ser distinto e singular entre iguais. (Arendt, 1999, p. 191)
}

A partir da revolução científica na Europa do séc. xvi ao xviii, e da consolidação de um novo status para a criança, o menor abandonado passa a ser considerado gradati- 
vamente um objeto de estudo beneficiado pelo reconhecimento da especificidade da criança, sobretudo a partir da obra de Rousseau. No fim do século XIX e início do século xx com a difusão do pensamento higienista na América Latina, mesmo sendo este ressignificado de diferentes formas, se estabelece e intensifica o processo de patologização (Luengo, 2010) do menor abandonado e sua caracterização como ameaça à ordem social recebendo frequentemente o estigma de menor infrator.

O menor abandonado foi considerado uma ameaça ao ideário e aos princípios do positivismo ${ }^{1}$ que fundamentavam o saber médico e o discurso jurídico. Ele seria a materialização da imprevisibilidade, da desordem social, uma ameaça ao progresso e à modernização da sociedade. Assim como o jogo clandestino e a vadiagem, o menor abandonado, ainda que resultante da mesma ordem modernizadora que supostamente ameaçava, segundo o pensamento jurídico-policial, deveria ser reprimido, mesmo que no caso específico tivesse que ser submetido aos castigos físicos ou à pedagogia corretiva em uma instituição educacional pública orientada pelo pensamento educacional Utilitarista.

\section{Pensamento educacional e o projeto de civilização do Estado Naci- onal na América Latina}

A América Latina passa na transição do século xix para o xx por profundas transformações que abrangem a formação e a consolidação dos estados nacionais com a construção de uma identidade nacional; a generalização e fortalecimento do republicanismo como sistema de governo e a generalização do trabalho assalariado como mão de obra predominante.

É o período da construção de inimigos internos com o processo de territorialização e medicalização dos problemas sociais ${ }^{2}$ através da generalização de uma lógica fundiária, locacional que isolava e cerceava as diferenças e os indesejáveis a partir do emprego de estratégias de alocação, isolamento e controle utilizados na esfera privada. Tratavase da difusão dos valores aristocráticos a todos os segmentos sociais, inclusive influenciando na formulação de um pensamento educacional que se manifestava ou materializava na diferenciação entre disciplinas e espaços escolares para meninos e meninas e na feminização do magistério.

O pensamento educacional que orientou no período estudado as ações de educadores e operadores jurídicos sobre a educação dos menores abandonados na América Latina, embora ligado às ideias dos pensadores europeus, como é o caso de Pestalozzi, Jeremy Bentham e Freud, diferenciaram-se pela forma como estas ideias foram recepci-

(1) «Com a criação do Homem, veio ao mundo o próprio preceito de início; e isto, naturalmente, é apenas outra maneira de dizer que o preceito de liberdade foi criado ao mesmo tempo, e não antes, que o homem. É da natureza do início que se comece algo novo, algo que não pode ser previsto a partir de coisa alguma que tenha ocorrido antes. Este cunho de surpreendente imprevisibilidade é inerente a todo início e a toda origem» (Arendt, 1999, p. 190).

(2) O uso do conceito medicalização está baseado no pensamento de Foucault (1999) que refere-se ao processo de aplicação do pensamento médico na abordagem de questões sociais. O conceito Medicalização está associado, no caso do presente artigo, a influência do pensamento médico na abordagem das questões educacionais. Em linhas gerais a medicalização pode ser compreendida como uma manifestação do organicismo e do Darwinismo Social. Sendo uma aplicação mecânica na abordagem das questões sociais, de ideias desenvolvidas no interior das ciências naturais, em desconsideração, ou desconhecimento as especificidades do objeto das ciências sociais. 
onadas. No caso das ideias de Freud, expressas em Mal estar na Civilização, os estudiosos, sobretudo os brasileiros, as associaram às políticas higienistas e à patologização das questões sociais, reduzindo ou ressignificando a obra de Freud a uma apologia da civilização.

A abordagem das questões sociais como patologia contou com a aplicação de uma interpretação tendenciosa do pensamento de Freud sobre cultura e civilização, pois, com relação à recepção de suas ideias, sobretudo no Brasil, é sintomático que seus primeiros defensores fossem psiquiatras, que também atuavam na área da criminologia.

O comportamento do menor considerado patológico seria uma atividade com motivações instintivas ou pulsionais devendo ser corrigido pela lei e pela educação, ou Pedagogia Ortopédica. Segundo Freud, que considerava a criança um perverso polimorfo, o abandono dos instintos primitivos, como pulsões ou compulsões, seria necessário para manutenção de uma sociedade civilizada. Assim, a Educação representaria o revigoramento, a ritualização de um sacrifício que todos deveriam fazer em prol dos benefícios ou contribuições da civilização. Esta relação custo-benefício está presente no consequencialismo que caracteriza e fundamenta o Método Lancaster, ou Método do Ensino Mútuo, adotado na América Latina e especificamente expresso na legislação brasileira desde 15 de outubro de 1827.

O pensamento educacional latino americano, construído na transição do séc. xix ao $x x$, tinha como base o conceito de civilização; como ferramenta civilizatória a escola; e como referência, ou paradigma, os valores da cultura europeia. Isto ficava evidente na escolha do objeto dos estudos comparados em educação realizados por professores latino americanos, que se concentravam no período estudado nas visitas técnicas à Espanha, a Portugal, Itália, França e Prússia, com especial atenção à experiência das escolas públicas destes países, para numa perspectiva melhorista, importar soluções para seus respectivos países.

Assim, a formulação de um pensamento educacional na América Latina foi marcada pela influência e transposição de ideias criadas e desenvolvidas a partir da tradição europeia. Merecem destaque:

1. O Utilitarismo na Educação como forma de construir um cidadão na consolidação dos Estados Nacionais Latino Americanos. Com relação a aplicação das ideias Utilitaristas de Bentham na Educação Profissional no Brasil é representativo o fato do Instituto de Menores Artesãos, criado pelo Decreto no 2745 de 13 de fevereiro de 1861, ocupar o mesmo espaço físico da Casa de Detenção fundada 5 anos antes. Principalmente se considerarmos que estas duas instituições, arquitetonicamente e funcionalmente, também seguiram as orientações do pensamento Benthamiano.

2. O Positivismo ou Cientificismo com a associação da educação à psicologia, inclusive experimental. Assim surgem no início do século propostas para a criação da Pedagogia Experimental, da Pedologia e da Pedotecnia. No Brasil Lourenço Filho destaca as contribuições do Dr. Ugo Pizzoli, considerado por Maria Montessori como o médico pioneiro na criação de uma Escola de Pedagogia Científica, na implantação do Laboratório de Psicologia e Pedagogia experimental da Escola Normal de São Paulo em 1914. Estas iniciativas se baseavam no pensamento expresso por Pizzoli ao abordar o que denominava ser a Ciência Pedagógica. Segundo este autor, a referida 
Ciência «deve encontrar, sobretudo na psicologia experimental, na Antropologia geral e especial, e na fisiologia do sistema nervoso, seus principais fundamentos positivos e científicos» (Pizzoli, 1900, p. 6).

3. A educação como instrumento de uma política eugênica. «Em 1918, o médico Victor Delfino, depois de estreito contato com as idéias eugênicas difundidas na Europa e de sua ligação com o médico brasileiro Renato Kehl, fundaria a Sociedade Eugênica Argentina» (Kinoshita, 2013, p. 49). Importante destacar que Renato Kehl além de Presidente e Fundador da Sociedade Eugênica de São Paulo no Brasil, participava ativamente com apresentação de trabalho e de pesquisas nos Congressos Nacionais de Educação realizados nos primórdios da República brasileira.

\section{As construções de um saber médico e do discurso Jurídico sobre a educação de menores abandonados na Argentina}

Nos últimos anos do séc. XIX a Argentina experimentou um crescimento populacional da ordem de $116 \%$, que se refletiu na intensificação e aprofundamento de uma crise urbana causada pela reduzida oferta de moradias populares. Posteriormente, nos primeiros anos do século $x x$, como resultado também da intensificação do processo imigratório, esta crise levou as camadas populares de Buenos Aires a protagonizar uma revolta urbana conhecida como «Huelga de Inquilinos» em 1908, ocorrida após a decretação de um aumento de impostos pela prefeitura de Buenos Aires, resultando em um aumento dos aluguéis que já consumiam $50 \%$ do salário dos trabalhadores. As condições precárias das moradias, agravada pela quantidade de moradores por unidade, também foram consideradas um motivo de revolta.

Segundo o Censo Municipal de 1904, em Buenos Aires, cada unidade habitacional denominada «conventillos» era em média ocupada por 11,5 moradores, caracterizandose como um lugar insalubre para adultos e principalmente para crianças. O mesmo problema habitacional foi observado nos igualmente insalubres «Cortiços» na cidade do Rio de Janeiro na virada do séc. XIX/XX. Este adensamento populacional concentrado em moradias populares localizadas em áreas sem saneamento básico foi responsável pela ocorrência de epidemias como a da febre amarela, e a do tifo ${ }^{3}$. Em ambas as cidades citadas os altos índices de mortalidade eram responsáveis pela existência de um grande número de órfãos e menores abandonados.

Este problema foi dramaticamente apresentado na pintura do artista uruguaio Juan Manuel Blanes em 1871, intitulado Un episódio de la febre amarilla em Buenos Aires. Trata-se, segundo registros policiais, do falecimento de uma jovem imigrante italiana moradora de um «conventillo» vitimada pela epidemia e que deixou órfão uma criança ainda de colo. Este quadro serviu como fonte para estudos sobre o impacto das epidemias no crescimento do número de menores abandonados em Buenos Aires.

(3) Segundo o Censo Municipal de Buenos Aires de 1904: «La estadística informaba que, de los 950.891 habitantes de la ciudad, 138.188 vivían en las 43.873 habitaciones que componen las 2.462 casas de inquilinato porteñas; es decir que, más del $10 \%$ de la población se albergaba en conventillos. Una familia vivía en una o -a lo sumo- dos piezas», recuperado em https://www.topia.com.ar/articulos/10903-la-ley-maldita [acceso: 02/04/2021]. 
A precária situação das moradias populares e a frequente ocorrência de epidemias tanto no Brasil quanto na Argentina foram utilizadas como argumentos do conhecimento médico-higienista para a fundamentação científica das ações autoritárias como a que resultou na Revolta da Vacina, ou contra a vacinação obrigatória na cidade do Rio de Janeiro entre 10 e 16 de novembro de 1904. Assim como para a formulação de um pensamento sobre a educação de menores abandonados nos casos da Ley 10903, conhecida como Ley do Patronato de Menores na Argentina em 1919, e do Código de menores no Brasil em 1927.

O caráter autoritário das ações orientadas por um pensamento educacional que se propõe civilizador na Argentina fica evidenciado na defesa que o Deputado do Partido Conservador Luis Agote faz da referida Ley 10903 ou Ley do Patronato dos Menores: El Estado tiene el derecho de secuestrar a los menores cuya conducta sea manifiestamente antisocial, pe-
ligrosa, antes de que cometan delitos... No hay en ello restricción de libertad civil: el menor no la tiene y
sólo se trata de sustituir la patria potestad por la tutela del Estado.

Como demonstração dos equívocos da aplicação da Ley do Patronato de Menores observamos que as instituições que receberiam os menores encaminhados pelos juízes a partir das prescrições e orientações da referida Lei tinham um histórico de altos índices de mortalidade. Estas instituições registraram em 32 anos a internação de 32.725 menores do ano 1880 a 1912. Neste período, o índice de mortalidade após as internações era de $51 \%$ dos menores. Foram realizadas em média 1.022 internações com 521 mortes por ano. Em média, 43 mortes por mês e 1,38 mortes de menores por dia só na capital Argentina.

Ainda segundo o representativo pensamento do Deputado Luis Agote, está explicitamente colocada a associação entre os argumentos apresentados nos discursos Jurídico-Policiais e o conhecimento médico. Nestes discursos é comum ou recorrente a necessidade de evitar a contaminação pelas ideias estrangeiras alheias e sem relação com a cultura argentina, resultantes do aumento da população de menores abandonados, filhos e filhas da imigração. Assim como no Direito e na Política verificamos a influência do pensamento médico higienista através da patologização de problemas ou manifestações sociais. Ainda segundo o referido Deputado:

Yo tengo la convicción profunda de que nuestra Ley falla si no llegamos a suprimir el cáncer social que representan 12 a 15 mil niños abandonados moral y materialmente que finalmente caen en la vagancia y después en el crimen. (Agote, 2004)

Após as manifestações ocorridas durante a «Huelga de Inquilinos», que teve grande participação dos menores das ruas de Buenos Aires, proibiu-se a livre circulação e os jogos recreativos dos menores abandonados. Inspirada na necessidade de manter a ordem e evitar, a partir de uma metáfora das epidemias, objeto do conhecimento médico, a contaminação ou o contágio das cidades por ideias difundidas por menores supostamente abandonados por pais imigrantes adeptos do socialismo, anarquismo, ou anarco-sindicalismo, como declaravam amplamente os periódicos que cobriram as manifestações populares de 1908 (Morlachetti, 2006).

Esta lei tinha impacto na educação desses menores abandonados pela generalização do comportamento e estigmatização em que se baseava. Entretanto, o desrespeito aos territórios e a movimentação sem limites faziam parte do cotidiano dos menores abandonados, mesmo que por esta razão fossem considerados uma constante ameaça à ordem instituída. 


\section{As construções de um saber médico e do discurso Jurídico sobre a educação de menores abandonados no Brasil}

Desde o segundo reinado, sobretudo com a atuação da Academia Imperial de Medicina ${ }^{4}$ já é possível identificar indícios da presença de um processo de medicalização das questões sociais e da educação. Mas, na República, a influência do saber médico na educação se aprofunda com a construção de argumentos em favor de uma profilaxia social fundamentada e amplamente difundida pelo pensamento higienista. Assim, quando as autoridades republicanas se referiam às ameaças, à moral e aos costumes, utilizavam, reveladoramente, termos como «epidemia», «cancro» e «degeneração».

A sociedade brasileira do início do séc. xx foi marcada por transformações demográficas decorrentes da intensificação da urbanização e do adensamento populacional como ocorreu na Argentina, resultante sobretudo da intensificação da imigração europeia ${ }^{5}$. Mas no Brasil a especificidade do emprego da imigração como forma de substituição do trabalho escravo levou ao incremento e aperfeiçoamento dos mecanismos e instrumentos de controle social dos quais merecem destaque o aumento do policiamento e a criação da lei contra a vadiagem.

No que se refere ao pensamento das elites republicanas observamos uma orientação modernizadora e a intenção de superar problemas educacionais deixados pelo período imperial como o índice de analfabetismo de $80 \%$ da população. Mas, as referências utilizadas no processo de modernização e no projeto civilizatório continuavam sendo europeias. $\mathrm{O}$ cientificismo positivista influenciou e orientou o pensamento jurídico e educacional no período estudado, manifestando-se como profilaxia social, conferindo uma racionalidade ao preconceito e às arbitrariedades cometidas na sociedade e nas escolas.

A medicina foi utilizada pela elite republicana como mais uma das ferramentas aplicadas à Educação para garantir a construção autoritária da disciplina, da ordem social e da segurança pública. Na Primeira República, o emprego do saber médico como instrumento de controle revestiu-se de um caráter pretensamente científico, manifestação de uma racionalidade organicista e positivista, que levou à patologização de questões sociais como a contravenção, o crescimento urbano e a Educação.

Neste sentido, a escola era considerada o instrumento apropriado para enfrentar os problemas gerados pelos hábitos das crianças humildes e permitir a padronização dos valores e hábitos por intermédio da disciplina do corpo e do espírito, indispensáveis às ações coordenadas exigidas pelas Fábricas. As relações entre a esfera pública e a esfera privada asseguravam a formação através da Educação de mão de obra moralmente

(4) Em discurso proferido pelo Dr. Correia na Academia Imperial de Medicina em 21 de dezembro de 1871, este ilustre membro afirmava que caberia à educação e à medicina: «Dar ao Homem, desde tenra idade a sua lei physica, social e moral a cumprir na família dos seus e na família da pátria» (Gondra, 1998, p. 37).

(5) «A falta de proteção ao "menor" se apresentava no aumento da taxa de mortalidade infantil, devido às precárias condições de higiene, à pobreza, à falta de informação das famílias e ao aumento da população em consequência da imigração estrangeira e de outros estados do país. No período de 1872 a 1899, houve um aumento da população correspondente a $279 \%$, e um aumento do índice de crianças que morriam ao nascer que alcançou 7,7\% entre os anos de 1895 e 1899». In Pereira da Silva, C. G. P. «Código Mello Mattos: Um olhar sobre a assistência e a proteção aos menores». Recuperado de https://www.maxwell.vrac.pucrio.br/14406/14406.PDF [acceso: 02/04/2021]. 
adequada aos processos de urbanização e industrialização. Assim, o espaço escolar foi utilizado como território de mediação entre esfera pública e esfera privada.

A influência do conhecimento médico na sociedade brasileira foi utilizada pela elite governante ligada, sobretudo, aos interesses da aristocracia rural para conferir cientificidade e justificar abordagens autoritárias e eurocêntricas em várias áreas. Na segurança pública houve a patologização dos crimes e contravenções, como o caso específico dos jogos clandestinos, considerados como epidemia. No planejamento urbano, o estabelecimento de uma geopolítica das epidemias, que justificou a reforma urbana de Pereira Passos. Na educação, o estabelecimento da noção de doenças morais e a interferência em questões pedagógicas, decorrente do combate à insalubridade nas instalações escolares e à criação neste espaço dos pelotões da saúde.

O saber médico ao assumir a formulação e difusão de regras e conceitos de higiene como função, levou os médicos a prescreverem também normas, valores, hábitos e costumes a serem ministrados no ambiente escolar com o objetivo de evitar «doenças morais» ou garantir profilaticamente a «higiene moral».

A construção jurídica da noção de infância carente que orientou o pensamento educacional sobre os menores abandonados no Brasil foi influenciada pelo préconceito e pela discriminação racial. O crescimento do número de crianças negras abandonadas nas instituições de caridade nos fins do século xix, juntamente com a ideia de que os negros libertos representariam um potencial inimigo doméstico, alimentada pelo medo de um processo de africanização da sociedade, existente desde o império, fez com que as crianças consideradas anteriormente como «sem família» passassem a ser tratadas como «menores abandonados», e a função das instituições misericordiosas, que antes deveriam se dedicar à reintegração dessas crianças, passou a se limitar a isolá-las da sociedade.

Esse processo se baseava numa racionalidade sanitarista que tanto se aplicava ao combate das doenças físicas quanto à repressão aos supostos «desvios», ou «doenças morais». Os menores abandonados se constituíam assim, numa ameaça de «contágio» moral $^{6}$. A Educação foi apresentada pela Medicina desde o segundo reinado como o principal remédio para a sociedade brasileira. Posteriormente a educação também foi apresentada como um instrumento da Eugenia.

O que caracterizou a influência do conhecimento médico e do discurso jurídico no pensamento educacional foi a promoção da despolitização das questões sociais, onde se inseriu a Educação. Os problemas deveriam perder sua dimensão política e passariam a ser tratados como questões técnicas que necessitariam apenas de profissionais específicos e conhecimento especializado. Esta é uma forma de promover e manter a elitização, como ficou claro no pensamento de um dos principais signatários do Manifesto dos Pioneiros da Educação de 1932, um dos membros da Sociedade Eugênica de São Paulo, fundada no ano 1918, o educador Lourenço Filho.

Salientamos que a pedagogia em ação se divide, como a arte de curar, em dois ramos principais, perfeitamente distintos: a clínica (meio de diagnóstico, de medida e verificação), que é a pedagogia

(6) Sobre os antecedentes históricos do conceito de «Higiene Moral» consultar a Reforma Couto Ferraz de 1854 (Decreto no 1331 A) e a Reforma Leôncio de Carvalho de 1879 (Decreto n 7247). 
experimental, e a terapêutica (intervenção positiva e direta sobre os indivíduos a curar ou a educar) que é a didática, lato sensu. (Filho, 1930, p. 121)

A Escola e a Educação de Menores abandonados foram utilizadas como espaço intermediário e de intermediação, entre a esfera privada e a esfera pública, entre a vida familiar, com as relações pré-políticas que a caracteriza, e a sociedade. A esfera privada era o lugar privilegiado para realizar indiretamente uma intervenção no espaço público. A partir deste momento a família começaria a assumir gradativamente um papel de coagente modelador ou formulador de um pensamento e de uma política educacional, assim como, com a criação da roda dos expostos, uma legislação e uma política para os menores abandonados tinham o objetivo de poupar e proteger as famílias.

Em 1918 as autoridades judiciais brasileiras firmaram um acordo entre os Ministérios do Comércio, da Agricultura, da Indústria e os Governos Estaduais no qual os menores abandonados seriam encaminhados para o Instituto Correcional Quinze de Novembro e para os Patronatos Agrícolas, tendo como objetivo promover a regeneração destes menores, supostamente degenerados pelas ruas, através do preparo e formação profissional para o trabalho organizado.

No caso específico dos Patronatos Agrícolas no Decreto 13.706 de 25 de julho de 1919, que trata da reorganização desta Instituição assistencialista, foi explicitado em seu art. 41 a «incapacidade moral» dos pais ou dos tutores como critério para admissão de menores abandonados. Há uma grande preocupação com o alastramento, disseminação de ideias socialistas e/ou anarquistas como uma epidemia. A ameaça das ideias anarquistas era vista como uma contaminação moral. Isso ocorre e já foi verificado desde os decretos de Leôncio de Carvalho e Couto Ferraz, ainda no império, relacionados às repercussões da Comuna de Paris, quando a grande preocupação era a Higiene Física e Moral. O mesmo teria ocorrido com a naturalização e/ou despolitização de ideias como propriedade privada e concorrência através da aplicação do método intuitivo na educação e da difusão do jus naturalismo no Direito.

A partir do ano de 1927 o Brasil passa a contar com uma legislação específica para os menores ${ }^{7}$, em uma perspectiva ainda positivista de «Saber para prever». «Prever para prover", que definiu inclusive quem deveria ser considerado menor abandonado. Tratava-se do chamado Código de Menores de 1927, Lei n 17943, também conhecida como Código Mello Mattos, que especificava no seu artigo n²6:

Consideram-se abandonados os menores de 18 anos: I- Que não tenham habitação certa nem meios de subsistência, por serem seus pais falecidos, desaparecidos ou desconhecidos ou por não terem tutor ou pessoa sob cuja guarda vivam. II- Que vivem em companhia de pai, mãe, tutor ou pessoas que se entreguem habitualmente à prática de atos contrários à moral e aos bons costumes. III- Que se encontrem em estado habitual de vadiagem, mendicância ou libertinagem. IV- Que frequentem lugares de jogo ou de moralidade duvidosa ou andem na companhia de gente viciosa ou de má vida. V- Que devido à crueldade, abuso de autoridade, negligência ou exploração dos pais, tutor ou encarregado de sua guarda sejam: a) vítimas de maus tratos-físicos e habituais ou castigos imoderados; b) privados habitualmente dos ali-

(7) O Direito do Menor, como foi denominado, somente no final do século XIX e que passa a ser reconhecido no âmbito internacional, com a instalação, no Estado Americano de Illinois, do Primeiro Tribunal de Menores do mundo, iniciativa que veio a influenciar a adoção de medidas semelhantes na Inglaterra (1905), Alemanha (1908), Portugal e Hungria (1911), França (1912), Argentina (1921), Japão (1922), Brasil (1923), Espanha (1924), México (1927) e Chile (1928), como podemos ler em Mendez (1998, p. 52). No que se refere a América Latina a primazia da instalação do $1^{\circ}$ Juizado de Menores coube a cidade do Rio de Janeiro em 1924. 
mentos ou dos cuidados indispensáveis à saúde; c) excitados habitualmente para gatunice, mendigagem ou libertinagem.

No Código Mello Mattos constam ainda artigos que caracterizam ou tipificam os referidos desvios que definem uma situação de abandono, onde estão presentes conceitos que não podem ser abordados cientificamente como seria exigido pelo próprio positivismo, que orientava a classe jurídica e a criação de um pensamento educacional voltado para o menor abandonado no período estudado.

\section{Considerações Finais: Convergências e Divergências}

Para abordarmos o pensamento educacional sobre a educação de menores abandonados na América Latina na transição dos sécs. xix/xx partimos das reflexões de Jürgen Schriewer especificamente de sua obra Comparación y explicación en el análisis de los sistemas educativos onde o referido estudioso estabeleceu três níveis de abstração para os estudos comparados. No primeiro nível ainda persiste uma preocupação em estabelecer diferenças e semelhanças, trata-se de uma leitura de superfície. Neste encontramos aproximações como a crise de moradia, o adensamento demográfico, as epidemias, a exploração da mão de obra imigrante e o grande crescimento do número de menores abandonados. Mas também, especificidades como a «Huelga de Inquilinos», a «Revolta da Vacina», a transição do sistema de trabalho escravo para a mão de obra assalariada.

Para além da descrição, narrativa ou observação direta de convergências e divergências, Schriewer aponta para a necessidade de num segundo nível identificar interesses, motivações, que possibilitarão uma compreensão do que foi observado. Neste caso, encontramos as motivações econômicas da formulação de um pensamento educacional que garanta o funcionamento do setor produtivo. Há a necessidade das elites na criação e manutenção contínua de um contingente de mão de obra, sobretudo no espaço urbano. Isto nós verificamos com estratégias punitivas e classificatórias empregadas tanto pelo saber médico quanto pelo discurso jurídico.

Num terceiro nível de abstração observamos o esforço de despolitização e naturalização dos problemas sociais, como o da educação de menores abandonados através da patologização e medicalização como modeladores do pensamento educacional. Dessa forma, a ação autoritária das elites republicanas na Argentina e no Brasil se apresentaria como um mal necessário. Neste nível, estamos tratando de questões e valores que persistem de forma semelhante às invariâncias, ou como afirma José de Sousa Martins, estamos diante do «poder do atraso».

Iniciando a trajetória do pensamento educacional pela influência da corrente filosófica do "Utilitarismo», passando pelos diferentes positivismos, chegando à expressão máxima da ideologia liberal com a Eugenia, os Estados Nacionais da América Latina na sua maioria compartilharam em diferentes manifestações ideias conservadoras na área educacional e na questão racial que se antagonizavam ao declarado projeto modernizador que ostentavam e que justificava suas respectivas existências.

Em suma, o que identificamos como convergências se referem ao pensamento predominante, hegemônico, que se manifesta numa tradição de vigilância e exclusão na educação de menores abandonados na América Latina. O que observamos como diver- 
gência é a reação de cada comunidade às ações uniformizadoras da materialização dos interesses das elites Latino Americanas.

\section{Referências}

Agote, L. (2004) «Sesión de diputados del 28 de agosto de 1919», en Los Derechos del Niño, la otra deuda interna. Recuperado de periodismosocial.org.ar [acceso: 02/04/2021].

Arendt, H. (1999) A condição humana. Rio de Janeiro, Forense universitária.

Brasil (1919) Decreto no 13.706, de 25 de julho de 1919. Dá nova organização aos patronatos agrícolas. Coleção de Leis do Brasil, Poder Executivo. Rio de Janeiro, RJ, v. 003, p. 146, 31 dez. 1919.

Brasil (1927) Código de Menores. Lei n 17943, de 12 de outubro de 1927.

Filho, Lourenço M. B. (1930) Educação Comparada. Brasília, MEC/INEP.

Foucault, M. (1999) Curso no Collège de France (1975-1976). São Paulo, Martins Fontes.

Freud, S. (1939) Moses and Monotheism. Londres, The Hogarth Press.

Freud, S. (2014) O homem Moisés e a religião monoteísta. Porto Alegre, LP\&M.

Gondra, J. G. (1998) Artes de civilizar. Medicina, higiene e educação escolar na corte Imperial. Rio de Janeiro, Editora UERJ.

Kinoshita, C. T. (2013) Um D. Quixote científico a pregar para uma legião de panças: os manuais escolares de Higiene à sombra da Eugenia (1923-1936). Dissertação para mestra em Educação. Orientadora: Dra. Heloísa Pimenta da Rocha. Universidade Estadual de Campinas.

Luengo, F. C. (2010) A vigilância punitiva: a postura dos educadores no processo de patologização e medicalização da infância. São Paulo, Cultura Acadêmica.

Mendez, E. G. (1998) Infância e Cidadania na América Latina. São Paulo, Hucitec.

Morlachetti, A. (2006) «Los niños y los oficios callejeros (Fines del siglo XIX-Principios del XX)». Recuperado de www.pelotadetrapo.org.ar [acceso: 02/04/2021].

Pereira da Silva, C. G. P. «Código Mello Mattos: Um olhar sobre a assistência e a proteção aos menores)». Recuperado de https://www.maxwell.vrac.puc-rio.br/14406/ 14406.PDF [acceso: 02/04/2021].

Pizzoli, U. (1900) II laboratorio di pedagogia scientifica in Crevalcore. Bologna, Stab. Tip. Zamorani e Albertazzi.

Schriewer, Jurgen (1990) Comparación y explicación en el análisis de los sistemas educativos. In: https://www.educacionyfp.gob.es/dam/jcr:fb21dad5-2024-4b7e9cb5-abb22254276f/re199004-pdf.pdf [acceso: 02/04/2021]. 

estudis comparatius del pensament educatiu a Amèrica Llatina

Resum: El menor abandonat representava una amenaça per a l'ideal i els principis del positivisme que fonamentaven el coneixement mèdic i el discurs jurídic. Va significar la materialització de la imprevisibilitat del desordre social, una amenaça per al progrés i la modernització de la societat. En aquest sentit, també amenaçava un pensament educatiu que es posava com a instrument principal, basat en l'optimisme pedagògic, la instal-lació i el manteniment dels estàndards europeus de civilització a I'Amèrica Llatina com a herència automàtica, dependència cultural, del període de colonització.

Paraules clau: Pensament educatiu, educació de menors abandonats, estudis comparats d'educació Ilatinoamericana, segles XIX i XX.

L'éducation des mineurs abandonnés selon le discours médico-juridique en Argentine et au Brésil dans le tournant des XIX e-XX e siècles. Une contribution aux études comparatives de la pensée éducative en Amérique latine

Résumé: Le mineur abandonné représentait une menace pour l'idéologie et les principes du positivisme qui sous-tendaient le savoir médical et le discours juridique. Il était la matérialisation de l'imprévisibilité du désordre social, une menace pour le progrès et la modernisation de la société. En ce sens, il menaçait aussi une pensée éducative qui se voulait instrument principal, fondé sur l'optimisme pédagogique, l'installation et le maintien de normes européennes de civilisation en Amérique latine en tant qu'héritage automatique, dépendance culturelle, de la période coloniale.

Mots-clés: Pensée éducative, éducation des mineurs abandonnés, études comparées d'éducation latinoaméricaine, XIX e et XX e siècles.

The education of abandoned children according to the forensic discourses in Argentina and Brazil during the transition between the nineteenth and twentieth centuries. A contribution to comparative studies of Latin American education

Abstract: The abandoned child posed a threat to the ideas and principles of positivism that underlay medical knowledge and legal discourse. The presence of abandoned children was the materialization of the unpredictability of social disorder, and a threat to progress and the modernization of society. It also threatened a concept of education based on optimism and the introduction and maintenance of European standards of civilization in Latin America as an automatic inheritance from the colonization period and a reflection of the continent's cultural dependence.

Keywords: Educational thinking, Education of abandoned child, comparative studies of nineteenth and twentieth-century Latin American education. 